\title{
Analysis of E-commerce Information Ecosystem Model Based on Block Chaining
}

\author{
Pan Deng*, Jing Zhong \\ Logistics Management Institute, Hunan Vocational College of Modern Logistics, Changsha 410001, China \\ *Corresponding Author email:49849977@qq.com
}

Keywords: block chain; e-commerce information; ecosystem model

\begin{abstract}
The model of e-commerce information ecosystem based on block chain can solve the defects of the current e-business information management mode. Based on this, this paper briefly analyzes the combination mode of the block chain and e-commerce information ecosystem, emphasizes the importance of the combination of the two, focuses on the structure of the model, the application of the various levels, as well as the solution of the common problems, and carries out a comprehensive study, in order to provide reference for the people concerned in the field of electric power business.
\end{abstract}

\section{Introduction}

With the upgrading of the level of economic globalization and the expansion of transaction volume, e-commerce information management has gradually become the focus of e-commerce management. The block chain is a distributed database system with the joint participation of each node. It will be applied to the management process, and the construction of an ecommerce information ecosystem model will effectively improve the management efficiency and security. Obviously, in order to improve the modernization level and enhance the competitiveness of the e-commerce field, it is necessary to study the way of building the model.

\section{The Combination Mode of Block Chain and E-commerce Information Ecosystem}

\subsection{Sharing mechanism and trust mechanism}

The survey shows that from 2015 to 2017, the scale of transactions paid by the third party is shown in Table 1:

Table 1 The size of the third party payment in --2018 2015

\begin{tabular}{cccc}
\hline Particular year & 2015 & 2016 & 2017 \\
\hline $\begin{array}{c}\text { Trade volume } \\
\text { (trillion yuan) }\end{array}$ & 2.5 & 6.2 & 9.4 \\
\hline
\end{tabular}

Table 1 shows that the amount of information in the field of e-commerce is increasing. In order to integrate the block chain and e-commerce information ecosystem, we should first establish a sharing and trust mechanism. The data information generated by the block chain needs to be backed up in the system. The system also needs to trust the block chain to ensure that information transmission can be carried out effectively. The main body of e-commerce is composed of 4 parts: suppliers, consumers, third party payment and electronic business platform. The information of these subjects is the main information of sharing and trust.

\subsection{Cooperative mechanism and security mechanism}

The survey shows that from 2015 to 2017, the security risks of various platforms in China's 200 e-commerce platforms are shown in Table 2: 
Table 2 Security risks of e-commerce platform in China in 2015 --2017

\begin{tabular}{cccc}
\hline Particular year & 2015 $(\mathrm{n}=200)$ & $2016(\mathrm{n}=200)$ & $2017(\mathrm{n}=200)$ \\
\hline Security risk $(\mathrm{n} / \%)$ & 16 & 25 & 51 \\
\hline
\end{tabular}

Table 2 shows that at present, the security of e-commerce platform information in China is gradually decreasing. Over time, the privacy of a large number of users will be leaked. The promotion of user property and personal safety, as well as the development of e-commerce in China is unfavorable. Therefore, in order to improve the level of information management in e-commerce, it is impossible to wait for the combination of block chain and e-commerce information ecosystem.

\section{Establishment and Application of E-commerce Information Ecosystem Model Based on Block Chain}

This part studies the establishment and application of the ecommerce information ecosystem model based on block chain based on the composition of the system model, the application of all levels of functions, and the three aspects of common problems and solutions.

\subsection{The composition of the system model}

The ecommerce information ecosystem model based on block chain is composed of core layer, technology layer, media layer, extension layer and peripheral layer, and the functions of different levels are different. In order to ensure secure communication at all levels, Merkle tree, hash algorithm and data encryption technology should be applied to the system construction process. Ensure that safety risks can be detected in time. In addition, it is equally important to set up a secure communication interface to ensure that all levels can communicate with each other.

\subsection{The application of each level function}

\subsubsection{Application of core layer and technology layer}

The core layer of the system consists of e-commerce enterprises, e-commerce platforms and consumers. The technical level is composed of interactive software and comment system. Take the core layer as an example: in order to bring the function of the block chain into full play, the security of the e-commerce information ecosystem model can be improved. The following method should be used to apply the model: when a user buys a product, the distributed system can collect information immediately, store it in the database, and send it to the e-commerce platform. After the e-business platform retains consumer information, e-commerce enterprises will acquire information and realize the management and storage of information.

\subsubsection{The application of the media layer and the extension layer}

The survey shows that from 2015 to 2017, the monthly average quantity of an e-commerce platform in China is shown in Table 3:

Table 3 Trading volume of an ecommerce platform in China from 2015 to 2017

\begin{tabular}{cccc}
\hline Particular year & 2015 & 2016 & 2017 \\
\hline $\begin{array}{c}\text { A single amount } \\
\text { (ten thousand) }\end{array}$ & 8549 & 9471 & 17484 \\
\hline
\end{tabular}

\subsection{Common problems and solutions}

Data security is the main problem facing the information ecosystem of e-commerce. In order to improve the security of the system, ensure that user information is not stolen. China's electricity supplier should apply the block chain to the process of building the system model to realize the protection of transaction information. Take China's A enterprises as an example, the enterprise is an e-commerce enterprise. In order to improve the security of information, enterprises have introduced 
block chain and established e-commerce information ecosystem. Before and after the establishment of the system, the occurrence of A enterprise information security risk is shown in Table 4:

Table 4 occurrence of information security risks of A enterprises before and after the establishment of the system

\begin{tabular}{ccc}
\hline System establishment & Pre establishment & After establishment \\
\hline Safety risk (second) & 6 & 1 \\
\hline
\end{tabular}

\section{Conclusion}

To sum up, this topic has pointed out the direction for the reform of e-commerce in the field of electronic commerce in China through the research on the model construction and application mode of electronic commerce information ecosystem based on block chain. In the future, in the field of e-commerce, we should give full consideration to the needs of enterprises, sellers and consumers. With the help of core layer, technology layer, media layer, extension layer and peripheral layer, a perfect ecosystem model is established. On the basis of improving the level of e-business information management modernization, we will provide better services for consumers.

\section{References}

[1] Meng Jun Na. Design and implementation of mobile e-business system based on Android platform, [J]. electronic design engineering, 2016,24 (08): 27-29+33.

[2] Ceng Yuan, LAN Chung Bao, and scarlet. SWOT analysis of the development of China's rural tourism electronic commerce system under the background of the big data age (English) [J]. Southern Agricultural Journal, 2014,45 (08): 1498-1506.

[3] Herbaut N, Negru N, Herbaut N, et al. A Model for Collaborative Blockchain-Based Video Delivery Relying on Advanced Network Services Chains[J]. IEEE Communications Magazine, 2017, 55(9):70-76.

[4] Li W, Peng C, Zhou X, et al. Application of the ecosystem model and Markov Chain Monte Carlo for parameter estimation and productivity prediction[J]. Ecosphere, 2016, 6(12):1-15.

[5] Fisher R, Ledwaba L, Hancke G, et al. Open Hardware: A Role to Play in Wireless Sensor Networks?[J]. Sensors, 2015, 15(3):6818-6844.

[6] Li W, Bhatia V, Cao K. Intelligent polar cyberinfrastructure: enabling semantic search in geospatial metadata catalogue to support polar data discovery[J]. Earth Science Informatics, 2015, 8(1):111-123.

[7] Droste H, Rost P, Doll M, et al. An adaptive 5G multiservice and multitenant radio access network architecture[J]. Transactions on Emerging Telecommunications Technologies, 2016, 27(9):1262-1270. 